\title{
SINTESIS DAN KARAKTERISASI SENYAWA OKSOTRINUKLIR $\left[\mathrm{Cr}_{3} \mathrm{O}\left(\mathrm{OOCC}_{6} \mathrm{H}_{5}\right)_{6}\left(\mathrm{H}_{2} \mathrm{O}\right)_{3}\right]\left(\mathrm{NO}_{3}\right) \cdot n \mathrm{H}_{2} \mathrm{O}$
}

\author{
Aldes Lesbani, Risfidian Mohadi \\ Jurusan Kimia FMIPA Universitas Sriwijaya \\ e-mail: aldeslesbani@yahoo.com
}

\begin{abstract}
ABSTRAK
Senyawa oksotrinuklir telah disintesis menggunakan kromium nitrat dan asam benzoat dalam etanol pada temperatur $80{ }^{\circ} \mathrm{C}$ selama 1 jam. Kristal senyawa oksotrinuklir hasil sintesis dikarakterisasi menggunakan spektrofotometer FTIR, ${ }^{1} \mathrm{H}$ NMR padat, X-Ray Difraktometer, TGA, dan MS dengan teknik ionisasi dingin. Hasil penelitian menunjukkan bahwa senyawa oksotrinuklir mempunyai vibrasi yang khas pada bilangan gelombang 671 $\mathrm{cm}^{-1}\left(v \mathrm{Cr}_{3}-\mathrm{O}\right)$. Identifikasi dengan spektrometer massa dalam asetonitril sebagai pelarut menunjukkan fragmentasi pada $m / z: 1021.83 \quad\left[\mathrm{Cr}_{3} \mathrm{O}\left(\mathrm{OOCC}_{6} \mathrm{H}_{5}\right)_{6}(\mathrm{MeCN})_{3}\right]^{+}, \quad 998,80$ $\left[\mathrm{Cr}_{3} \mathrm{O}\left(\mathrm{OOCC}_{6} \mathrm{H}_{5}\right)_{6}(\mathrm{MeCN})_{2}\left(\mathrm{H}_{2} \mathrm{O}\right)\right]^{+}, \quad 980,79 \quad\left[\mathrm{Cr}_{3} \mathrm{O}\left(\mathrm{OOCC}_{6} \mathrm{H}_{5}\right)_{6}(\mathrm{MeCN})_{2}\right]^{+}, \quad 939,73$ $\left[\mathrm{Cr}_{3} \mathrm{O}\left(\mathrm{OOCC}_{6} \mathrm{H}_{5}\right)_{6}(\mathrm{MeCN})\right]^{+}$. Puncak yang lebar dan besar pada spektrum ${ }^{1} \mathrm{H}$ NMR menunjukkan bahwa kromium yang bersifat paramagnetic di dalam senyawa. Pola XRD menunjukkan bahwa senyawa oksotrinuklir adalah kristalin dan hasil termogravimetri menunjukkan senyawa oksotrinuklir stabil sampai suhu $174{ }^{\circ} \mathrm{C}$ dan mempunyai 5 mol air kristal. Dari hasil karakterisasi FTIR, ${ }^{1} \mathrm{H}$ NMR, XRD, TGA, dan MS dapat disimpulkan bahwa senyawa yang terbentuk adalah $\left[\mathrm{Cr}_{3} \mathrm{O}\left(\mathrm{OOCC}_{6} \mathrm{H}_{5}\right)_{6}\left(\mathrm{H}_{2} \mathrm{O}\right)_{3}\right]\left(\mathrm{NO}_{3}\right) \cdot 5 \mathrm{H}_{2} \mathrm{O}$.
\end{abstract}

Kata Kunci: senyawa oksotrinuklir, kromium, benzoate

\section{SYNTHESIS AND CHARACTERISATION OF OXOTRINUCLEAR COMPOUND $\left[\mathrm{Cr}_{3} \mathrm{O}\left(\mathrm{OOCC}_{6} \mathrm{H}_{5}\right)_{6}\left(\mathrm{H}_{2} \mathrm{O}\right)_{3}\right]\left(\mathrm{NO}_{3}\right) \cdot n \mathrm{H}_{2} \mathrm{O}$}

\begin{abstract}
Oxotrinuclear compound was synthesized using chromium nitrate and benzoic acid in ethanol at $80{ }^{\circ} \mathrm{C}$ for $1 \mathrm{~h}$. The crystal of oxotrinuclear compound was characterized using FT-IR spectroscopy, cold spray ionization mass spectroscopy, ${ }^{1} \mathrm{H}$ NMR solid, X-Ray Difractometer and thermogravimetry analysis. The results showed that the the oxotrinuclear compound has specific vibration for at wavenumber $671 \mathrm{~cm}^{-1}\left(v \mathrm{Cr}_{3}-\mathrm{O}\right)$. Identification of oxotrinuclear compound using cold spray ionization mass spectrometer in acetonitrile as a solvent showed fragmentation at $\mathrm{m} / \mathrm{z}: 1021.83 \quad\left[\mathrm{Cr}_{3} \mathrm{O}\left(\mathrm{OOCC}_{6} \mathrm{H}_{5}\right)_{6}\right.$ $\left.(\mathrm{MeCN})_{3}\right]^{+}, \quad 998.80 \quad\left[\mathrm{Cr}_{3} \mathrm{O}\left(\mathrm{OOCC}_{6} \mathrm{H}_{5}\right)_{6}(\mathrm{MeCN})_{2}\left(\mathrm{H}_{2} \mathrm{O}\right)\right]^{+}, \quad 980.79 \quad\left[\mathrm{Cr}_{3} \mathrm{O}\left(\mathrm{OOCC}_{6} \mathrm{H}_{5}\right)_{6}\right.$ $\left.(\mathrm{MeCN})_{2}\right]^{+}, 939.73\left[\mathrm{Cr}_{3} \mathrm{O}\left(\mathrm{OOCC}_{6} \mathrm{H}_{5}\right)_{6}(\mathrm{MeCN})\right]^{+}$. The broad and large peak in ${ }^{1} \mathrm{H}$ NMR spectrum indicated of paramagnetic properties of chromium in the oxotrinuclear compound. XRD pattern showed that it is a crystalline compound. Thermal analysis showed that oxotrinuclear compound is stable until $174{ }^{\circ} \mathrm{C}$ and has 5 mol water of crystallization. From characterization by FTIR, ${ }^{1} \mathrm{H}$ NMR, XRD, TGA, and MS can be concluded that the compound formed is $\left[\mathrm{Cr}_{3} \mathrm{O}\left(\mathrm{OOCC}_{6} \mathrm{H}_{5}\right)_{6}\left(\mathrm{H}_{2} \mathrm{O}\right)_{3}\right]\left(\mathrm{NO}_{3}\right) \cdot 5 \mathrm{H}_{2} \mathrm{O}$.
\end{abstract}

Keywords: oxotrinuclear compound, chromium, benzoic 


\section{PENDAHULUAN}

Pengembangan material baru berbasis gabungan senyawa organik dan anorganik terus menjadi topik penelitian yang menarik untuk diteliti disebabkan sifat-sifat yang khas yang dimilikinya seperti sifat magnet, sifat sensor, sifat luminescence ataupun sifat fisik lainnya (Lesbani, 2008). Material gabungan ini dapat berupa senyawa-senyawa hibrid maupun senyawa-senyawa organologam. Salah satu senyawa yang terus dipelajari sifat dan kegunaannya bagi kepentingan hidup manusia adalah senyawa oksotrinuklir. Senyawa oksotrinuklir merupakan senyawa yang tersusun atas ikatan antara tiga atom logam dengan oksigen-oksigen sehingga dikenal dengan istilah senyawa okso (Gavrilenko, et al, 2004). Senyawa ini terkenal dengan rumus umum $\left[\mathrm{M}_{3}\left(\mu_{3}-\mathrm{O}\right)\left(\mathrm{O}_{2}\left(\mathrm{CR}_{6}\right) \mathrm{L}_{3}\right]^{+}\right.$ dimana $\mathrm{M}=$ atom logam yang biasanya logam-logam blok $\mathrm{d}, \mathrm{R}=$ alkil atau aril, $\mathrm{L}$ = ligan). Senyawa-senyawa oksotrinuklir banyak dimanfaatkan sebagai material magnet dan sebagai sensor karena sifat elektrokimia dari senyawa ini yang karakteristik (An, et al, 1999) maupun sebagai katalis dalam reaksi-reaksi organik (Sumner and Steinmetz, 1985). Sifat lain yang menonjol dari senyawa ini adalah pemanfaatannya sebagai material luminescence dan sebagai building block untuk supramolekul (Lesbani, et al, 2008).

Senyawa oksotrinuklir yang biasa dijumpai adalah logam-logam kromium, besi, mangan, ruthenium, rodium, iridium, kobat dan vanadium (Castro, et al, 1996) dengan berbagai kombinasi $\mathrm{R}$ dan $\mathrm{L}$ yang ada.Ada pula senyawa oksotrinuklir yang memiliki campuran valensi logam misalnya campuran ruthenium, rodium dan iridium (Belyaev and Simanova, 2004).

Pada penelitian ini dilaporkan sintesis senyawa oksotrinuklir $\left[\mathrm{Cr}_{3} \mathrm{O}\right.$ $\left.\left(\mathrm{OOCC}_{6} \mathrm{H}_{5}\right)_{6}\left(\mathrm{H}_{2} \mathrm{O}\right)_{3}\right]\left(\mathrm{NO}_{3}\right) \cdot n \mathrm{H}_{2} \mathrm{O}$ dan karakterisasinya secara spektroskopi, difraksi, dan studi stabilitas termal. Senyawa oksotrinuklir dengan atom kromium seperti $\left[\mathrm{Cr}_{3} \mathrm{O}(\mathrm{OOCR})_{6}(\mathrm{~L})_{3}\right]^{+}$ telah banyak dilaporkan dengan $\mathrm{R}=$ asetat $\left(\mathrm{CH}_{3}\right)$ (Fouda and Rempel, 1979), propionat $\left(\mathrm{C}_{2} \mathrm{H}_{5}\right)$ (Fujihara et al, 1998) dengan variasi L yang pada umumnya air atau piridin. Senyawa oksotrinuklir $\left[\mathrm{Cr}_{3} \mathrm{O}\left(\mathrm{OOCC}_{6} \mathrm{H}_{5}\right)_{6}(\mathrm{~L})_{3}\right]+$ dimana $\mathrm{L}$ adalah piridin telah disintesis dan dikarakterisasi oleh Harton, et al (1994) dan Vlachos, et al (2004) dimana L adalah piridin atau metanol dan anionnya adalah klorat atau metanol-nitrat sehingga penelitian ini akan memodifikasi L dengan air dan nitrat sebagai anion. Prosedur sintesis dalam rangka mengganti ligan piridin dan metanol dengan air dimodifikasi dari prosedur yang dilakukan oleh Harton, et al (1994) dan Vlachos, et al (2004).

\section{METODOLOGI PENELITIAN}

\section{Alat dan Bahan}

Alat-alat yang dipergunakan dalam penelitian ini meliputi peralatan gelas seperti beker gelas ukuran $250 \mathrm{~mL}$, gelas ukur $100 \mathrm{~mL}$, spatula kaca, corong, pengaduk magnetik, hotplate, dan pompa vakum. Untuk proses karakterisasi digunakan spektrofotometer FT-IR Jasco, spektrometer massa Perkin Elmer TurboMass, spektrometer NMR Bruker ${ }^{1} \mathrm{H}$ Magic Angle Spinning $121 \mathrm{MHz}$, difraktometer XRD Rigaku Corp dan TGDTA Thermo Plus, Rigaku.

Bahan-bahan kimia yang digunakan dalam penelitian ini meliputi kromium nitrat, asam benzoat, etanol, metanol, dan akuades. Bahan-bahan kimia tersebut dibeli langsung dari supplier dan dipergunakan langsung tanpa proses pemurnian lebih lanjut buatan Merck dan Aldrich. 


\section{Sintesis Senyawa Oksotrinuklir $\left[\mathrm{Cr}_{3} \mathrm{O}\left(\mathrm{OOCC}_{6} \mathrm{H}_{5}\right)_{6}\left(\mathrm{H}_{2} \mathrm{O}\right)_{3}\right]\left(\mathrm{NO}_{3}\right) n \mathrm{H}_{2} \mathrm{O}$}

Sintesis senyawa oksotrinuklir $\left[\mathrm{Cr}_{3} \mathrm{O}\left(\mathrm{OOCC}_{6} \mathrm{H}_{5}\right)_{6}\left(\mathrm{H}_{2} \mathrm{O}\right)_{3}\right]\left(\mathrm{NO}_{3}\right) \cdot n \mathrm{H}_{2} \mathrm{O}$ dilakukan atas prosedur Harton, et al (1994) dan Vlachos, et al (2004) dengan sedikit modifikasi. Sebanyak $8 \mathrm{~g}$ $\mathrm{Cr}\left(\mathrm{NO}_{3}\right)_{3} 9 \mathrm{H}_{2} \mathrm{O}(0.02 \mathrm{~mol})$ dan $9,04 \mathrm{~g}$ asam benzoat $(0,04$ mol $)$ dilarutkan dalam $10 \mathrm{~mL}$ etanol dan campuran dipanaskan pada temperatur $80{ }^{\circ} \mathrm{C}$ sambil diaduk dengan pengaduk magnetik. Campuran diaduk terus selama 1 jam untuk diperoleh kristal berwarna hijau. Kristal hijau yang diperoleh disaring dan dicuci dengan akuades lalu dikeringkan dengan cara divakum selama 24 jam. Kristal hijau hasil pengeringan dengan vakum di rekristalisasi dengan metanol untuk menghasilkan kristal hijau yang siap dikarakterisasi.

\section{Karakterisasi Senyawa Oksotrinuklir}

Senyawa oksotrinuklirhasil sintesis dikarakterisasi menggunakan spektroskopi FT-IR dengan metoda pelet $\mathrm{KBr}$ dan dianalisis dalam rentang bilangan gelombang 400-4000 $\mathrm{cm}^{-1}$. Pengukuran menggunakan spektrometer massa dilakukan dengan metoda ionisasi dingin menggunakan nitrogen cair dan sampel senyawa oksotrinuklir dilarutkan dalam asetonitril. Pengukuran ${ }^{1} \mathrm{H}$ NMR padat dilakukan dengan metoda MAS (magic angle spinning) dengan tabung zirkonia sebagai tempat sampel. Pengukuran menggunakan difraksi sinar $\mathrm{X}$ melalui teknik powder dimana sampel senyawa oksotrunuklir digerus secara halus lalu dianalisis dengan XRD pada kecepatan scanning $1 \%$ menit. Analisis termogravimetri dilakukan dengan menggunakan senyawa $\alpha-\mathrm{Al}_{2} \mathrm{O}_{3}$ sebagai standar dengan nitrogen sebagai gas inert.

\section{HASIL DAN PEMBAHASAN}

Senyawa oksotrinuklir disintesis dengan mudah pada kondisi udara terbuka tanpa bantuan gas inert seperti yang dilakukan oleh kebanyakan sintesis senyawa-senyawa organologam (Szafran et al, 1991). Senyawa oksotrinuklir yang terbentuk berwarna hijau dengan rendemen yang diperoleh sebesar $16 \%$. Walaupun rendemen yang terbentuk kecil, akan tetapi proses pengerjaan dengan modifikasi prosedur Vlachos, et al (2004) memberikan peluang terhadap proses sintesis senyawa oksotrinuklir yang sederhana dan mudah dilakukan. Senyawa hasil sintesis kemudian dikarakterisasi menggunakan spektroskopi FT-IR untuk mengetahui keberadaan gugus $\mu$-3 kromium-oksigen yang khas pada senyawa oksotrinuklir simetris (Ohto et al, 1995). Spektra FTIR senyawa oksotrinuklir hasil sentesis disajikan pada Gambar 1.

Keberadaan gugus benzoat teridentifikasi pada bilangan gelombang $1614-1623 \mathrm{~cm}^{-1}$ yang merupakan ciri khas senyawa aromatik. Senyawa nitrat yang merupakan counterion teridentifikasi pada bilangan gelombang $683 \mathrm{~cm}^{-1}$. Ciri khas senyawa oksotrinuklir yang simetris ditandai oleh adanya gugus $\mu-3$ kromiumoksigen yang muncul pada bilangan gelombang $671 \mathrm{~cm}^{-1}$ (Johnson, et al, 1981). Selanjutnya senyawa oksotrinuklir hasil sintesis diidentifikasi lebih lanjut menggunakan spektrometer massa dimana sampel senyawa oksotrinuklir dilarutkan terlebih dahulu dengan asetonitril (Bergen et al, 1993). Pola fragmentasi spektrum massa senyawa oksotrinuklir hasil sintesis disajikan pada Gambar 2. 
Sintesis dan karakterisasi senyawa oksotrinuklir... (Aldes Lesbani dan Rifsidian Mohadi)

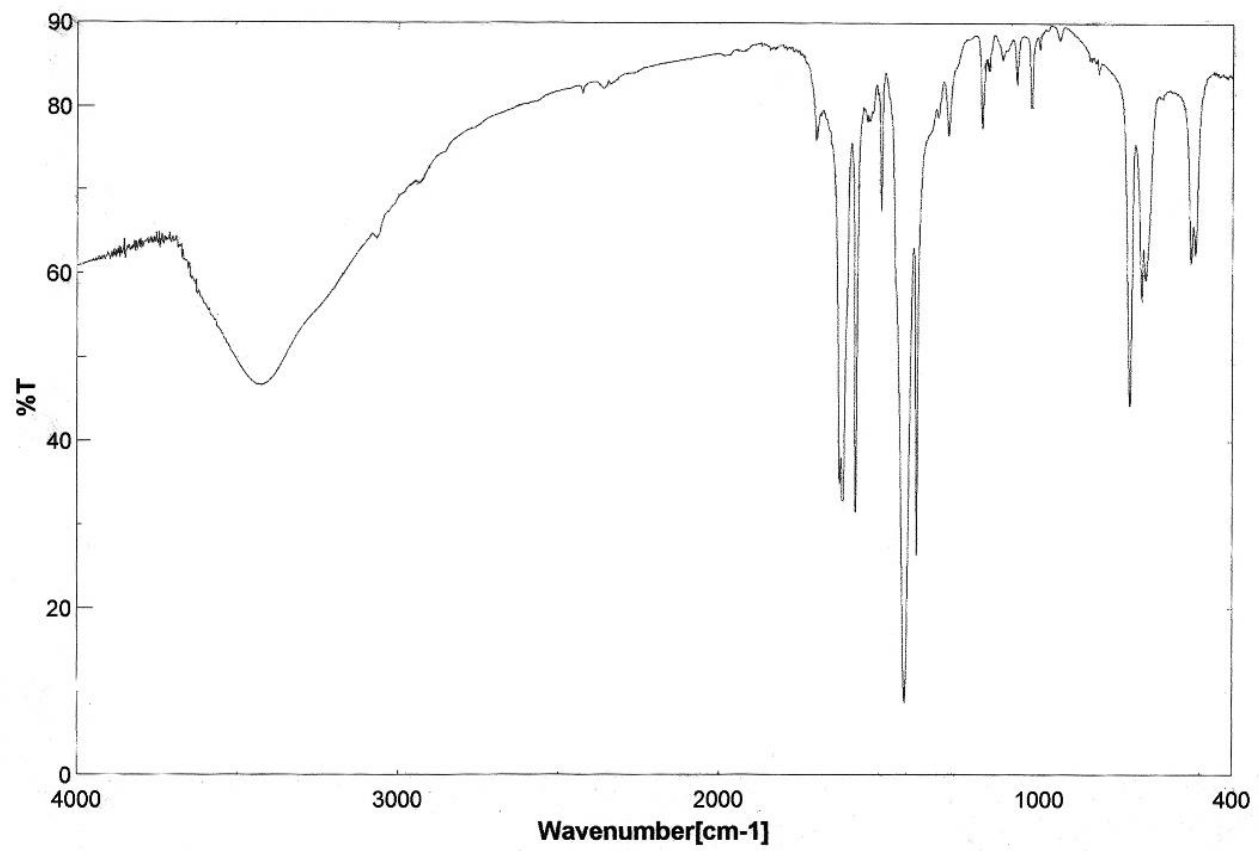

Gambar 1. Spektra FT-IR senyawa oksotrinuklir hasil sintesis

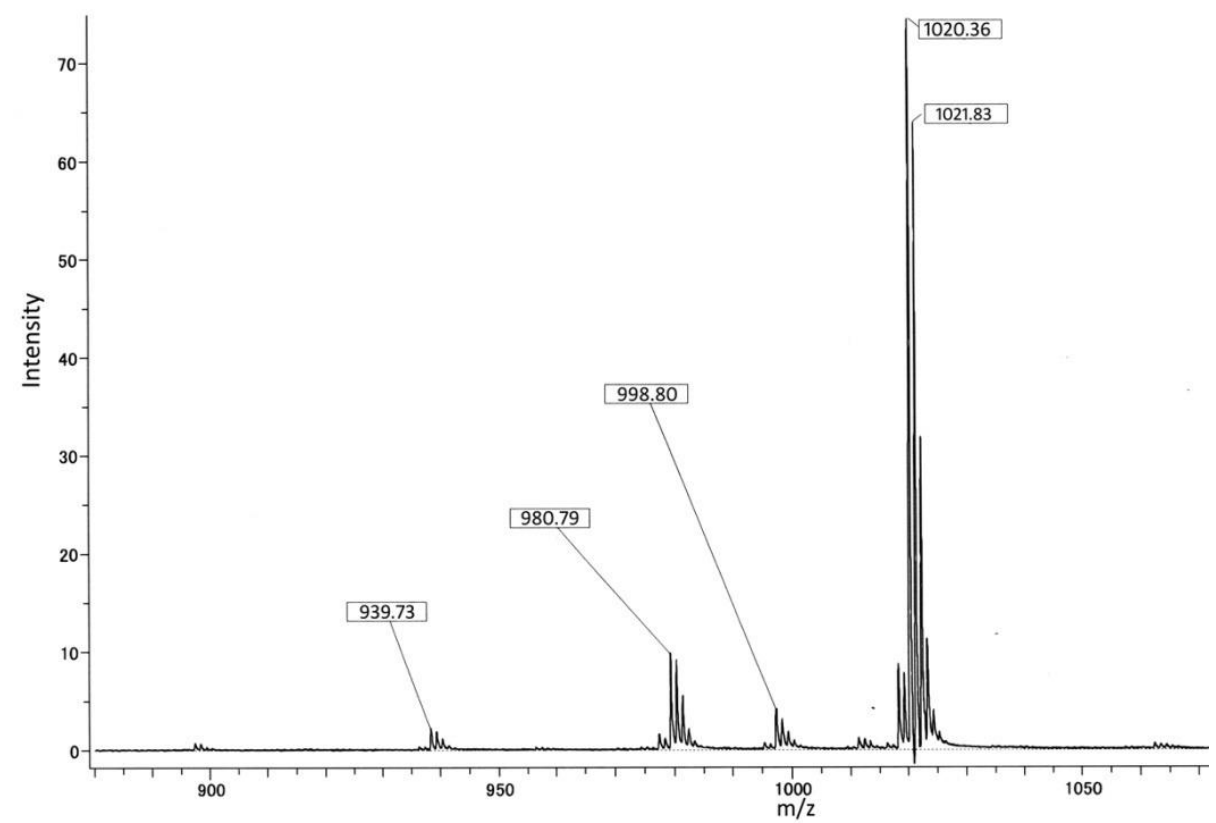

Gambar 2. Spektrum massa senyawa oksotrinuklir hasil sintesis

Pada Gambar 2 terlihat bahwa adanya empat puncak fragmentasi molekul pada senyawa oksotrinuklir hasil sintesis yakni pada $\mathrm{m} / \mathrm{z}, 1021,83 ; 998,80$; 980,79; dan 939,73. Ke empat fragmentasi tersebut teridentifikasi sebagai $\quad\left[\mathrm{Cr}_{3} \mathrm{O}\left(\mathrm{OOCC}_{6} \mathrm{H}_{5}\right)_{6}(\mathrm{MeCN})_{3}\right]^{+}$ pada $m / z 1021,83, \quad\left[\mathrm{Cr}_{3} \mathrm{O}\left(\mathrm{OOCC}_{6} \mathrm{H}_{5}\right)_{6}\right.$
$\left.(\mathrm{MeCN})_{2}\left(\mathrm{H}_{2} \mathrm{O}\right)\right]^{+} \quad$ pada $m / z 998,80$, $\left[\mathrm{Cr}_{3} \mathrm{O}\left(\mathrm{OOCC}_{6} \mathrm{H}_{5}\right)_{6}(\mathrm{MeCN})_{2}\right]^{+} \quad$ pada $m / z 980,79$, dan $\quad\left[\mathrm{Cr}_{3} \mathrm{O}\left(\mathrm{OOCC}_{6} \mathrm{H}_{5}\right)_{6}\right.$ $(\mathrm{MeCN})]^{+}$pada $\mathrm{m} / z$ 939,73. Senyawa nitrat yang merupakan counterion tidak teridentifikasi pada pengukuran ini. Senyawa air yang bertindak sebagai ligan yang terikat pada tiga atom kromium 
pada pengukuran dengan spektrometer massa tergantikan oleh asetonitril sebagai pelarut senyawa oksotrinuklir $\left[\mathrm{Cr}_{3} \mathrm{O}\left(\mathrm{OOCC}_{6} \mathrm{H}_{5}\right)_{6}\left(\mathrm{H}_{2} \mathrm{O}\right)_{3}\right]\left(\mathrm{NO}_{3}\right)$ sehingga menghasilkan puncak tertinggi pada $\mathrm{m} / \mathrm{z}$ 1021,83 yakni puncak dari $\left[\mathrm{Cr}_{3} \mathrm{O}\left(\mathrm{OOCC}_{6} \mathrm{H}_{5}\right)_{6}(\mathrm{MeCN})_{3}\right]^{+}$. Dari data hasil pengukuran dengan spektrometer massa ini terlihat bahwa senyawa oksotrinuklir $\quad\left[\mathrm{Cr}_{3} \mathrm{O}\left(\mathrm{OOCC}_{6} \mathrm{H}_{5}\right)_{6}\left(\mathrm{H}_{2} \mathrm{O}\right)_{3}\right]$ $\left(\mathrm{NO}_{3}\right) n \mathrm{H}_{2} \mathrm{O}$ berhasil disintesis. Untuk selanjutnya karakterisasi dilakukan untuk melihat sifat-sifat senyawa oksotrinuklir baik sifat fisik maupun sifat kimia. Pengukuran dilakukan dengan menggunakan spektrometer ${ }^{1} \mathrm{H}$ NMR, difraktometer XRD, dan pengukuran stabilitas senyawa oksotrinuklir menggunakan analisis termogravimetri. Spektra ${ }^{1} \mathrm{H}$ NMR senyawa oksotrinuklir $\left[\mathrm{Cr}_{3} \mathrm{O}\left(\mathrm{OOCC}_{6} \mathrm{H}_{5}\right)_{6}\left(\mathrm{H}_{2} \mathrm{O}\right)_{3}\right]\left(\mathrm{NO}_{3}\right) n \mathrm{H}_{2} \mathrm{O}$ tersaji pada Gambar 3.

Pada spektra ${ }^{1} \mathrm{H}$ NMR senyawa oksotrinuklir seperti yang tersaji diatas terlihat bahwa terjadi pelebaran spektra dimulai dari pergeseran kimia -20 ppm hingga $60 \mathrm{ppm}$. Pelebaran spektra ${ }^{1} \mathrm{H}$ NMR ini dimungkinkan karena senyawa oksotrinuklir yang disintesis dalam penelitian ini mengandung atom kromium sebagai atom pusat dari senyawa organologam yang terbentuk. Atom kromium yang memiliki konfigurasi elektron terluar $3 \mathrm{~d}^{5} 4 \mathrm{~s}^{1}$ dimungkinkan memiliki sifat paramagnetik (Shriver and Atkins, 2006). Apabila sifat paramagnetik muncul dalam senyawa organologam atau senyawa kompleks yang di sintesis, maka pengukuran menggunakan spektroskopi NMR akan memberikan puncak yang melebar yang disebabkan sifat tersebut (Belmore et al, 1994). Selanjutnya dilakukan pengukuran menggunakan difraktometer XRD terhadap senyawa oksotrinuklir hasil sintesis. Pola XRD senyawa oksotrinuklir $\left[\mathrm{Cr}_{3} \mathrm{O}(\mathrm{OOC}\right.$ $\left.\left.\mathrm{C}_{6} \mathrm{H}_{5}\right)_{6}\left(\mathrm{H}_{2} \mathrm{O}\right)_{3}\right]\left(\mathrm{NO}_{3}\right) \cdot n \mathrm{H}_{2} \mathrm{O}$ tersaji pada Gambar 4.

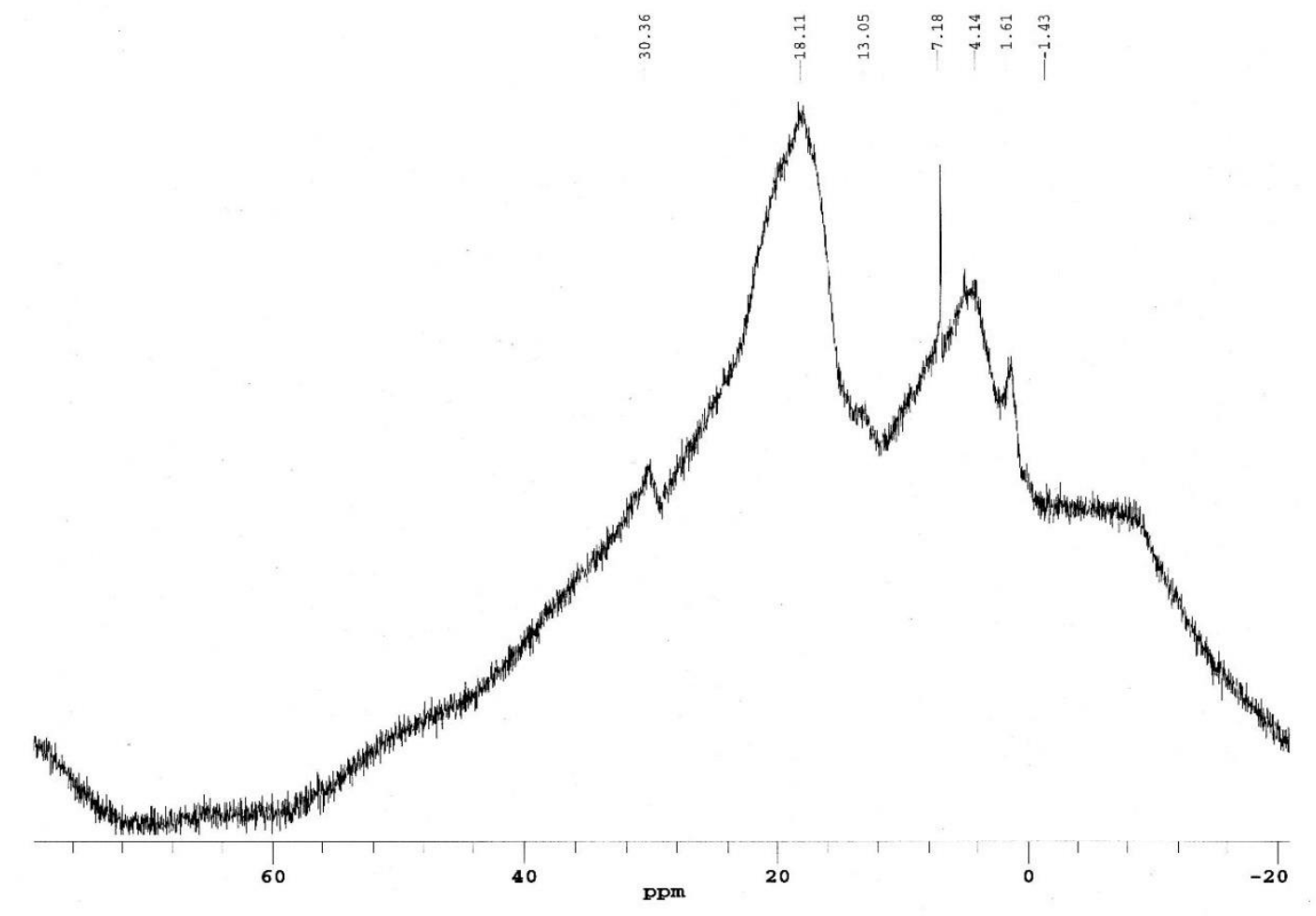

Gambar 3. Spektra ${ }^{1} \mathrm{H}$ NMR (MAS) senyawa oksotrinuklir $\left[\mathrm{Cr}_{3} \mathrm{O}\left(\mathrm{OOCC}_{6} \mathrm{H}_{5}\right)_{6}\left(\mathrm{H}_{2} \mathrm{O}\right)_{3}\right]$ $\left(\mathrm{NO}_{3}\right) \cdot n \mathrm{H}_{2} \mathrm{O}$ 


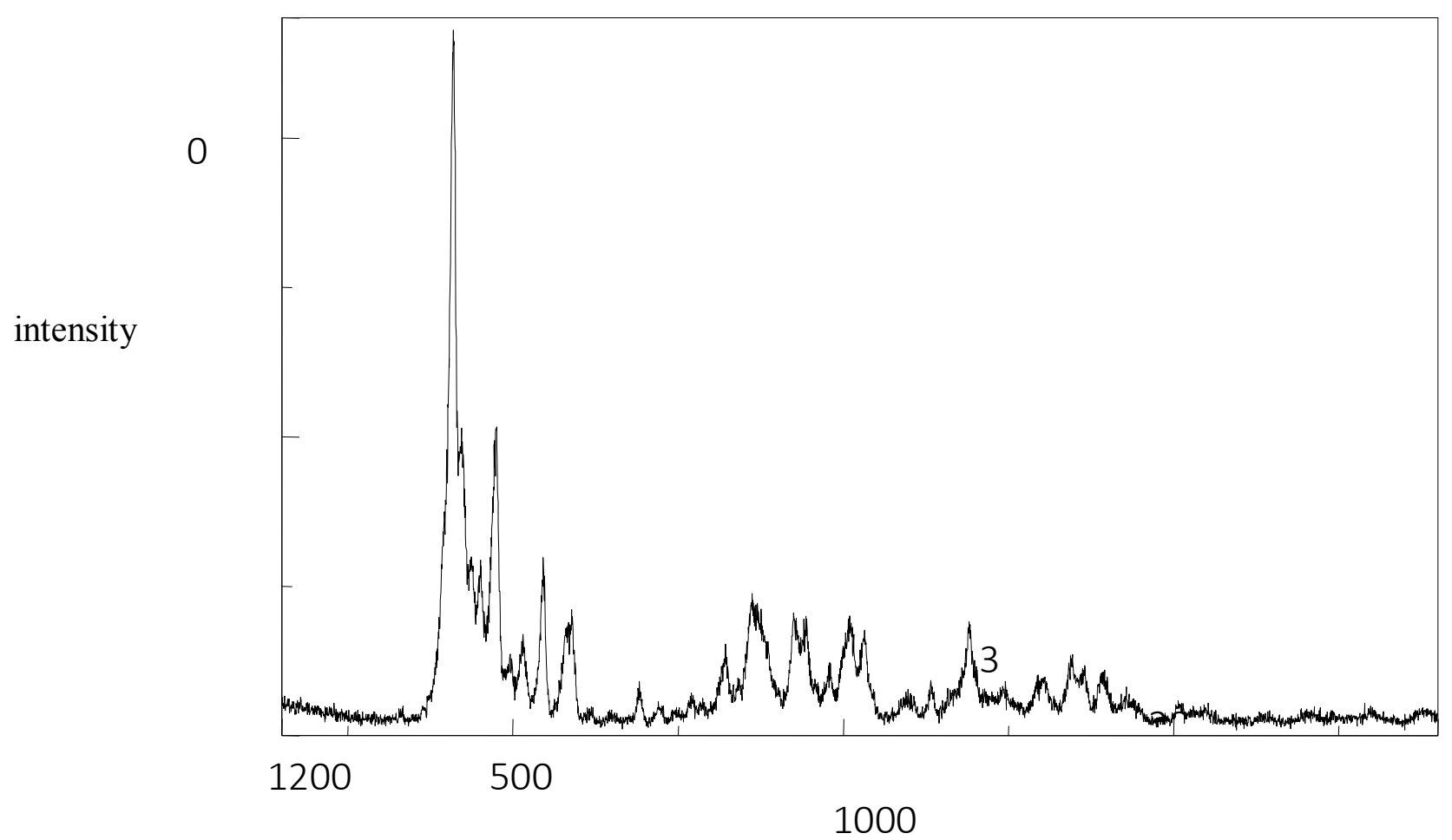

Gambar 4. Pola XRD senyawa oksotrinuklir $\left[\mathrm{Cr}_{3} \mathrm{O}\left(\mathrm{OOCC}_{6} \mathrm{H}_{5}\right)_{6}\left(\mathrm{H}_{2} \mathrm{O}\right)_{3}\right]\left(\mathrm{NO}_{3}\right) \cdot n \mathrm{H}_{2} \mathrm{O}$

Pola XRD senyawa oksotrinuklir $\left[\mathrm{Cr}_{3} \mathrm{O}\left(\mathrm{OOCC}_{6} \mathrm{H}_{5}\right)_{6}\left(\mathrm{H}_{2} \mathrm{O}\right)_{3}\right]\left(\mathrm{NO}_{3}\right) \cdot n \mathrm{H}_{2} \mathrm{O}$ seperti yang tersaji pada Gambar 4 terlihat bahwa adanya puncak-puncak difraksi pada $2 \theta$ dibawah 10. Puncakpuncak difraksi $2 \theta$ dibawah 10 tersebut menunjukkan bahwa senyawa oksotrinuklir hasil sintesis memiliki kristalinitas yang tinggi. Hal ini sesuai dengan studi difraksi sinar X kristal tunggal terhadap senyawa oksotrinuklir simetris $\quad\left[\mathrm{Cr}_{3} \mathrm{O}\left(\mathrm{O}_{2} \mathrm{CPh}\right)_{6}(\mathrm{py})_{3}\right] \mathrm{ClO}_{4}$ (Harton, et al, 1994) sesuai dengan Gambar 5.

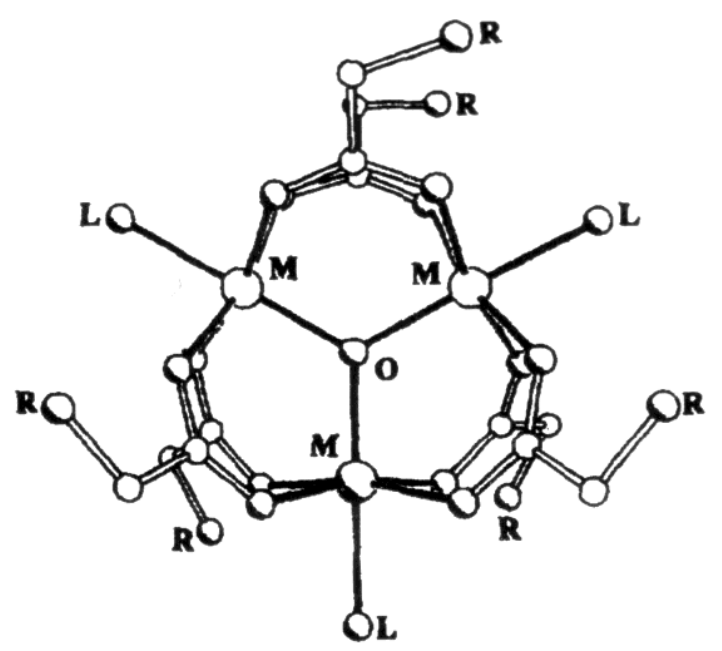

Gambar 5. Struktur senyawa oksotrinuklir simetris dengan $M=$ atom pusat, $L=$ ligan. 
Stabilitas senyawa oksotrinuklir $\left[\mathrm{Cr}_{3} \mathrm{O}\left(\mathrm{OOCC}_{6} \mathrm{H}_{5}\right)_{6}\left(\mathrm{H}_{2} \mathrm{O}\right)_{3}\right]\left(\mathrm{NO}_{3}\right) \cdot n \mathrm{H}_{2} \mathrm{O}$

dapat diketahui melalui pengukuran menggunakan termogravimetri. Senyawa organologam mengandung gugus organik yang tidak tahan terhadap temperatur tinggi yang menyebabkannya berbeda dengan senyawa-senyawa anorganik. Hal ini yang menyebabkan perlunya pengukuran stabilitas termal senyawa oksotrinuklir $\quad\left[\mathrm{Cr}_{3} \mathrm{O}\left(\mathrm{OOCC}_{6} \mathrm{H}_{5}\right)_{6}\left(\mathrm{H}_{2} \mathrm{O}\right)_{3}\right]$ $\left(\mathrm{NO}_{3}\right) \cdot n \mathrm{H}_{2} \mathrm{O}$ menggunakan termogravimetri. Pola termogravimetri hasil pengukuran terhadap senyawa oksotrinuklir hasil sintesis disajikan pada Gambar 6.

Pada pola termogravimetri senyawa oksotrinuklir hasil sintesis seperti yang tersaji pada Gambar 6 terlihat bahwa pada tahap awal pengukuran pada temperatur $35^{\circ} \mathrm{C}$ terjadi pengurangan berat sampel akibat pemanasan sebesar $5,52 \%$. Perpanjangan waktu hingga 85 menit pada temperatur $36{ }^{\circ} \mathrm{C}$ dengan kenaikan temperatur yang lambat menyebabkan pengurangan sampel sebesar 7,57\%. Senyawa oksotrinuklir $\quad\left[\mathrm{Cr}_{3} \mathrm{O}\left(\mathrm{OOCC}_{6} \mathrm{H}_{5}\right)_{6}\left(\mathrm{H}_{2} \mathrm{O}\right)_{3}\right]$ $\left(\mathrm{NO}_{3}\right) \cdot n \mathrm{H}_{2} \mathrm{O}$ mengalami dekomposisi ditandai dengan pola termogravimetri yang mulai menurun pada suhu $174{ }^{\circ} \mathrm{C}$ dengan kehilangan berat akibat dekomposisi sampel senyawa oksotrinuklir sebanyak $10 \%$. Pada keadaan ini jumlah air kristal dapat dihitung dari persentase sampel yang hilang terdekomposisi dengan asumsi berat molekul air yakni $18 \mathrm{~g} / \mathrm{mol}$. Hasil perhitungan menghasilkan nilai air kristal dari senyawa oksotrinuklir $\left[\mathrm{Cr}_{3} \mathrm{O}\right.$ $\left.\left(\mathrm{OOCC}_{6} \mathrm{H}_{5}\right)_{6}\left(\mathrm{H}_{2} \mathrm{O}\right)_{3}\right]\left(\mathrm{NO}_{3}\right) \cdot n \mathrm{H}_{2} \mathrm{O}$ yakni sebesar $5 \mathrm{~mol}$ sehingga senyawa oksotrinuklir hasil sintesis memiliki rumus molekul $\quad \mathrm{Cr}_{3} \mathrm{O}(\mathrm{O}$ $\left.\left.\mathrm{OCC}_{6} \mathrm{H}_{5}\right)_{6}\left(\mathrm{H}_{2} \mathrm{O}\right)_{3}\right]\left(\mathrm{NO}_{3}\right) \cdot 5 \mathrm{H}_{2} \mathrm{O}$. Pada kenaikan temperatur hingga $400{ }^{\circ} \mathrm{C}$ maka jumlah sampel yang terdekomposisi mendekati setengah dari jumlah sampel sehingga sesuai dengan asumsi bahwa senyawa organologam memiliki stabilitas termal yang tidak tinggi bila dibandingkan dengan senyawa-senyawa anorganik pada umumnya (Weller, 2002). Dari data karakterisasi yang telah dilakukan dapat dinyatakan bahwa senyawa oksotrinuklir $\quad\left[\mathrm{Cr}_{3} \mathrm{O}(\mathrm{OO}\right.$ $\left.\left.\mathrm{CC}_{6} \mathrm{H}_{5}\right)_{6}\left(\mathrm{H}_{2} \mathrm{O}\right)_{3}\right]\left(\mathrm{NO}_{3}\right) \cdot n \mathrm{H}_{2} \mathrm{O} \quad$ telah berhasil disintesis dengan mudah dan memiliki stabilitas termal hingga $174{ }^{\circ} \mathrm{C}$.

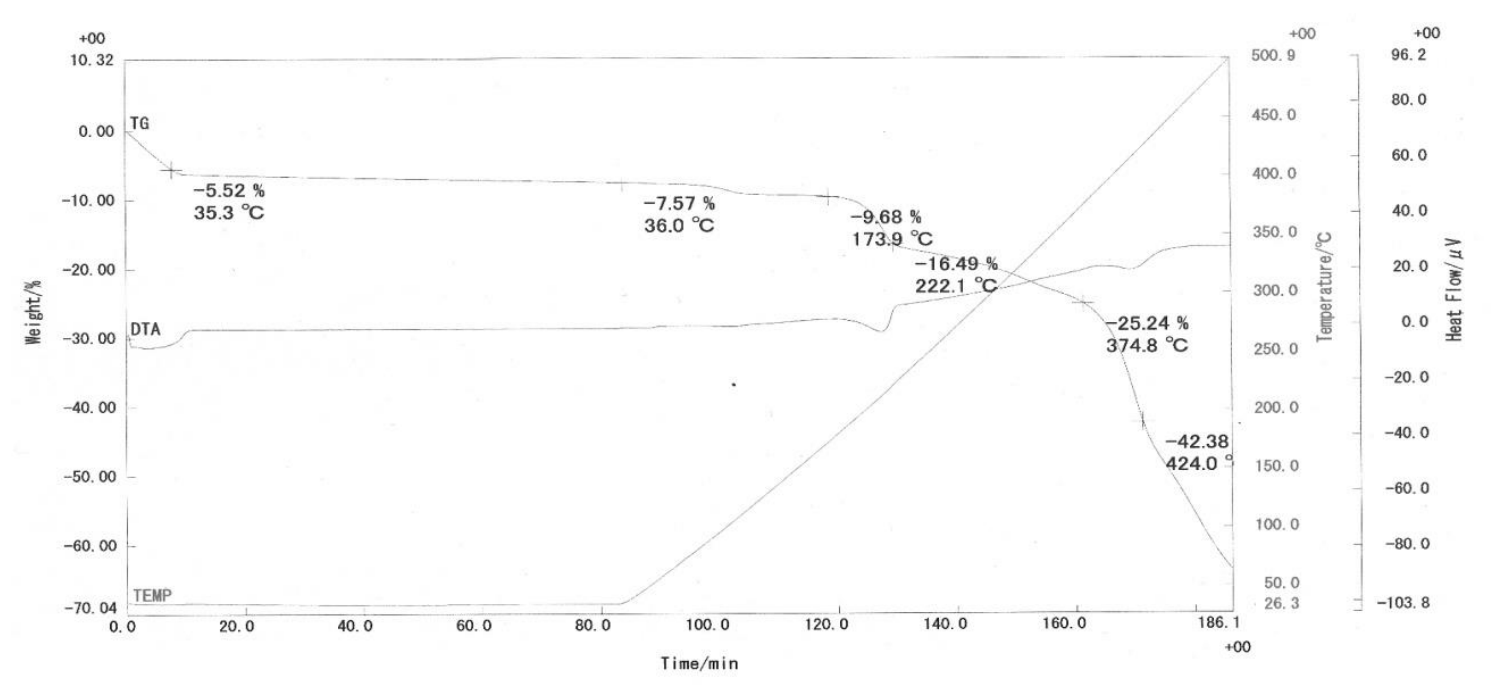

Gambar 6. Pola termogravimetri senyawa oksotrinuklir $\left[\mathrm{Cr}_{3} \mathrm{O}\left(\mathrm{OOCC}_{6} \mathrm{H}_{5}\right)_{6}\left(\mathrm{H}_{2} \mathrm{O}\right)_{3}\right]$ $\left(\mathrm{NO}_{3}\right) \cdot n \mathrm{H}_{2} \mathrm{O}$ 


\section{KESIMPULAN}

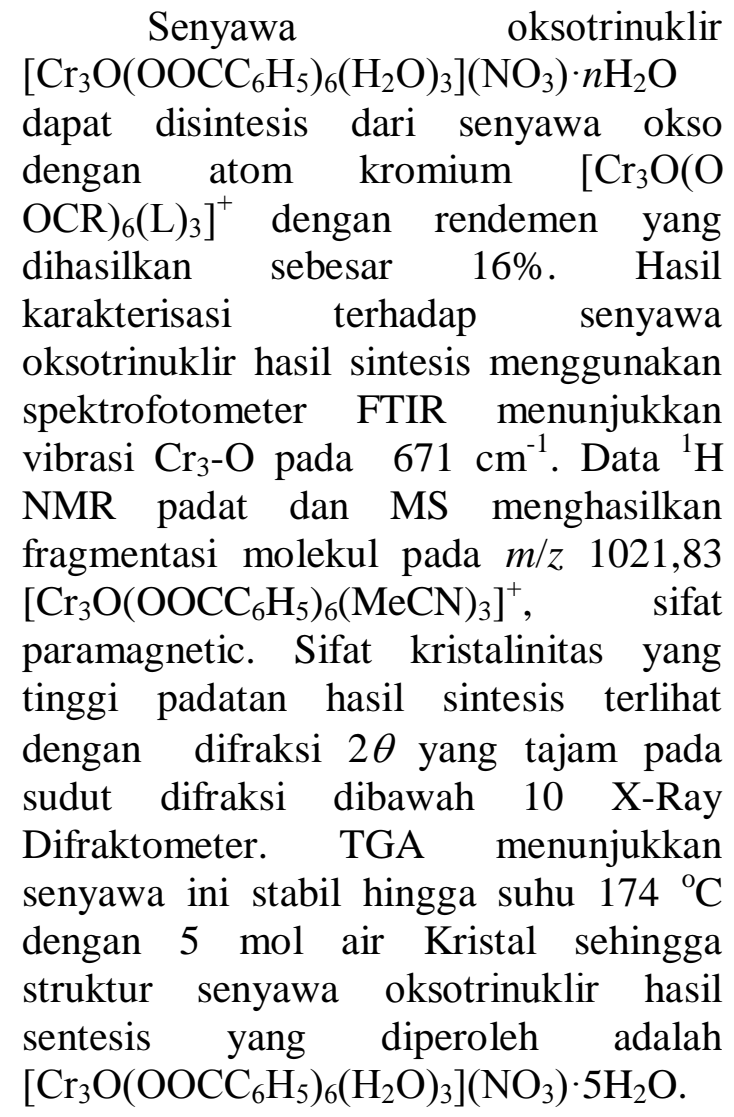

\section{UCAPAN TERIMA KASIH}

Disampaikan kepada Prof. N. Mizuno, The University of Tokyo atas pemakaian peralatan analisis untuk karakterisasi senyawa oksotrinuklir.

\section{DAFTAR PUSTAKA}

An. J, Chen.Z.D, Bian. J, Jin. X.L, Wang.S.X, Xu. G.X, 1999, Synthesis Crystal Structures and Magnetic Properties of Trinuclear Oxo-Centered Manganese Complexes of the General Formula $\left[\mathrm{Mn}_{3} \mathrm{O}\left(\mathrm{O}_{2} \mathrm{CR}\right)_{6} \mathrm{~L}_{3}\right]^{\mathrm{z+}}(\mathrm{R}=\mathrm{Me}, \mathrm{Et}, \mathrm{Ph}$, $\mathrm{CH}_{2} \mathrm{Cl}_{2} ; \mathrm{L}=3$-methylpiridine or water $\mathrm{Z}=1,0)$, Inorganica Chimica Acta, 287, 82-88.
Belmore. K, Madison. X.J, Harton. A, Vincent. J.B, 1994, Carbon-13 NMR Studies of Oxo-Centered Trinuclear Chromium(III) Complexes of the General Formula $\left[\mathrm{Cr}_{3} \mathrm{O}\left(\mathrm{O}_{2} \mathrm{CR}\right)_{6}(\mathrm{~L})_{3}\right]^{+}(\mathrm{R}=\mathrm{Me}, \mathrm{Ph} ; \mathrm{L}$ $=\mathrm{H}_{2} \mathrm{O}$, py), Spectrochimica Acta, 50A, 2365-2370.

Belyaev.A.N, Simanova. S.A, 2004, Ru, $\mathrm{Rh}$, and Ir Trinuclear MixedValence Oxygen-Bridged Carboxylate Complexes, Russian Journal of Coordination Chemistry, 30, 184-193.

Bergen. A.V.D, Colton. R, Percy. M, West. B.O, 1993, Electrospray Mass Spectrometric Study of $\left[\mathrm{M}_{3} \mathrm{O}(\mathrm{RCOO})_{6} \mathrm{~L}_{3}\right]^{+}$Cations $(\mathrm{M}=$ $\mathrm{Cr}, \mathrm{Fe} ; \mathrm{L}=\mathrm{H}_{2} \mathrm{O} . \mathrm{MeOH}$, py), Inorganic Chemistry, 32, 34083411 .

Castro. S.L, Streib.W.E, Sun. J.S, Christou. G, 1996, Structural, Spectroscopic, and Magnetochemical Characterization of the Trinuclear Vanadium (III) Carboxylates $\quad\left[\mathrm{V}_{3} \mathrm{O}\left(\mathrm{O}_{2} \mathrm{CR}\right)_{6} \mathrm{~L}_{3}\right]$ $\left(\mathrm{ClO}_{4}\right) \quad(\mathrm{R}=$ Various groups; $\mathrm{L}=$ Pyridine, 4-Picoline, 3,5-Lutidine), Inorganic Chemistry, 35, 44624468 .

Fouda.S.A, Rempel. G.L, 1979, $\mu_{3}$-OxoTriruthenium Acetat Cluster Complexes as Catalysts for Olefin Hydrogenation, Inorganic Chemistry, 18, 1-8. 
Fujihara. T, Aonahata. J, Kumakura. S, Nagasawa. A, Murakami. K, Ito. T, 1998, Kinetic Study on the Substitution of Dimethylacetamide for The Terminal Aqua Ligands in the Trinuclear Chromium(III) Complexes $\quad\left[\mathrm{Cr}_{3}\left(\mu_{3}-\mathrm{O}\right)\left(\mu-\mathrm{RCO}_{2}\right)_{6}\right.$ $\left.\left(\mathrm{H}_{2} \mathrm{O}\right)_{3}\right]^{+}\left(\mathrm{R}=\mathrm{H}, \mathrm{CH}_{3}, \mathrm{CH}_{3} \mathrm{CH}_{2}\right.$, $\mathrm{CH}_{2} \mathrm{Cl}, \quad \mathrm{CHCl}_{2}, \quad \mathrm{CH}_{3} \mathrm{OCH}_{2}$, $\left(\mathrm{CH}_{3}\right)_{3} \mathrm{C}, \quad \mathrm{CH}_{2} \mathrm{ClCH}_{2}, \quad\left(\mathrm{CH}_{3} \mathrm{CH}_{2}\right)$ $\mathrm{CH})$. Elucidation of the Mechanism From the Activation Volumes and the Substituent Effects of Bridging Carboxylate Ligands, Inorganic Chemistry, 37, 3779-3784.

Gavrilenko.K.S, Addison.A, Thompson. L, Pavlishchuk. V.V, 2004, Magnetic Characteristic of Trinuclear Complexes $\quad\left[\mathrm{M}_{3} \mathrm{O}\left(\mathrm{CH}_{3} \quad \mathrm{COO}\right)_{6}\right.$ $\left.(\mathrm{pz})_{3}\right]^{+}(\mathrm{M}=\mathrm{Fe}, \mathrm{Cr} ; \mathrm{pz}=$ pyrazine $)$, Theoretical and Experimental Chemistry, 40, 214-216.

Harton.A, Nagi.M.K, Glass.M.M, Junk.P.C, Atwood. J.L, Vincent. J.B, 1994, Synthesis and Characterization of Symmetric and unsymmetric Oxo-Bridged Trinuclear Chromium Benzoate Complexes: Crystal and Molecular Structure of $\left[\mathrm{Cr}_{3} \mathrm{O}\left(\mathrm{O}_{2} \mathrm{CPh}\right)_{6}(\mathrm{py})_{3}\right]$ $\mathrm{ClO}_{4}$, Inorganica Chimica Acta, 217, 171-174.

Johnson. M.K, Powell. D. B, Cannon. R.D, 1981, Vibrational Spectra of Carboxylato Complexes-III. Trinuclear 'basic' Acetates and Formates of Chromium(III), Iron (III) and Other Transition Metals, Spectrochimica Acta, 37A, 9951006.

Lesbani, A, 2008, Syntheses of Ionic Crystals of PolyoxometalateOrganometallic Complex and Sorption Properties, Ph.D Dissertation, The University of Tokyo.
Lesbani.A, Kawamoto. R, Uchida. S, Mizuno. N, 2008, Control of Structures and Sorption Properties of Ionic Crystals of $\mathrm{A}_{2}\left[\mathrm{Cr}_{3} \mathrm{O}\left(\mathrm{OOCC}_{2} \mathrm{H}_{5}\right)_{6}\left(\mathrm{H}_{2} \mathrm{O}\right)_{3}\right]_{2}[\alpha \mathrm{Si}$ $\mathrm{W}_{12} \mathrm{O}_{40}$ ] ( $\mathrm{A}=\mathrm{Na}, \mathrm{K}, \mathrm{Rb}, \mathrm{NH}_{4}, \mathrm{Cs}$, TMA), Inorganic Chemistry, 47, 3349-3357.

Ohto.A, Yamamoto.A.T, Abe. M, Ito. T, Sasaki. Y, Umakoshi. K, Cannon. R.D, 1995, Structure and Vibrational Spectra of Trinuclear Metal Cluster Complexes, A Question of Symmetry, Chemistry Letters, 97-98.

Shriver and Atkins, 2006, Inorganic Chemistry, $4^{\mathrm{t}}$ Edition, Oxford University Press, Oxford.

Sumner Jr. C.E, Steinmetz. G.R, 1985, Isolation of Oxo-Centered Cobalt(III) Clusters and Their Role in The Cobalt Bromide Catalyzed Autoxidation of Aromatic Hydrocarbons, Journal of American Chemical Society, 107, 6124-6126.

Szafran. Z, Pike R.M, Singh. M. M, 1991, Microscale Inorganic Chemistry, John Willey and Sons, New York.

Vlachos.A, Psycharis. V, Raptopoulou. C.P, Lalioti. N, Sanakis. Y, Diamantopoulos. G, Fardis. M, Karayanni. M, Papavassiliou. G, Terzis. A, 2004, A Nearly Symmetric Trinuclear Chromium (III) Oxo Carboxylate Assembly: Preparation, Molecular and Crsytal Structure, and Magnetic Properties of $\quad\left[\mathrm{Cr}_{3} \mathrm{O}\left(\mathrm{O}_{2} \mathrm{CPh}\right)_{6}(\mathrm{MeOH})_{3}\right]$ $\left(\mathrm{NO}_{3}\right) \cdot 2 \mathrm{MeOH}, \quad$ Inorganica Chimica Acta, 357, 3162-3172.

Weller. M.T, 2002, Inorganic Materials Chemistry, Oxford Chemistry Premiers, Oxford University Press, UK. 